\title{
Structural, Morphological, Optical and Electrical Properties of Cu-Doped PbS Nanofilms
}

\author{
Rui Li, ${ }^{1,2}$ Wei Li, ${ }^{1,2^{*}}$ Mengting Liu, ${ }^{1,2}$ Qinyu He, ${ }^{1,2}$ Yinzhen Wang, ${ }^{1,2}$ Qiuqiang Zhan ${ }^{3}$ and Teng Wang ${ }^{4}$
}

$\mathrm{PbS}$ nanofilms with different $\mathrm{Cu}$ doping concentrations $(0,1,2,3$ and 4 at. \%) were deposited. The effects of $\mathrm{Cu}$ concentration on the structural, morphological, optical and electrical properties of $\mathrm{PbS}$ nanofilms were studied. With the increasing dopant content, we find that the crystallite size decreases, the shape of crystal particles changes, the optical band gap increases, the resistivity and carrier concentration change non-monotonously. $2 \% \mathrm{Cu}$-doped $\mathrm{PbS}$ film has the optimum value of theoretical band gap for absorbing sunlight, and $3 \% \mathrm{Cu}-\mathrm{doped} \mathrm{PbS}$ film has the lowest resistivity and the highest carrier concentration.

Keywords: PbS nanofilms; Cu doping; Optical properties; Electrical properties; Morphology

Received 11 January 2019, Accepted 29 March 2019

DOI: $10.30919 / \mathrm{esmm} 5 \mathrm{f} 217$

\section{Introduction}

Lead sulfide $(\mathrm{PbS})$ is an important narrow-bandgap semiconductor with the band gap of $0.4 \mathrm{eV}$ and the exciton radius of $18 \mathrm{~nm}$ at room temperature. ${ }^{1}$ Due to its wide band adjustment range, ${ }^{2} \mathrm{PbS}$ materials not only have important research value in basic theory, but also have high application value in the fields of optoelectronic devices and biomedical imaging. Such as detectors, ${ }^{3-5}$ gas sensors, ${ }^{6-8}$ solar cells, ${ }^{9}, 10$ and bio sensors. ${ }^{11}$

Because of the abundant reserves, the low price, and the strong absorption capacity in visible and near-infrared light, $\mathrm{PbS}$ is a potential for the absorption layer of solar cells. ${ }^{12}$ Recently, PbS films have been prepared for solar energy applications by using different techniques such as chemical bath deposition (CBD), ${ }^{13,14}$ successive ionic layer adsorption and reaction (SILAR), ${ }^{15}$ spray pyrolysis, ${ }^{16,}{ }^{17}$ vacuum evaporation, ${ }^{18}$ pulsed laser deposition(PLD) ${ }^{19}$ and electrodeposition. ${ }^{20}$ Among these techniques, CBD method is relatively simple, quick, economical, and can be applied to an industrial scale compared to other processes. In addition, many physical and chemical properties of $\mathrm{PbS}$ nanostructures can be altered by introducing various impurities. ${ }^{21-23}$

It has been reported earlier that metallic dopant ions strongly

'Guangdong Engineering Technology Research Center of Efficient Green Energy and Environmental Protection Materials, School of Physics and Telecommunication Engineering, South China Normal University, Guangzhou, 510006, China

2Guangdong Provincial Key Laboratory of Quantum Engineering and Quantum Materials, Guangzhou 510006, China

${ }^{3}$ Centre for Optical and Electromagnetic Research, Guangdong Provincial Key Laboratory of Optical Information Materials and Technology, South China Academy of Advanced Optoelectronics, South China Normal University, 510006 Guangzhou, China

${ }^{4}$ School of Computer, South China Normal University, Guangzhou 510006, China

*E-mail:tolwwt@163.com influences the opto-electrical properties of pure $\mathrm{PbS}^{24,25} \mathrm{Cu}$ ion has an ionic radius of $0.73 \AA$, which is less than that of $\mathrm{Pb}$ ion $(1.19 \AA)$. Therefore, it is expected that more $\mathrm{Cu}$ ions can be accommodated into the $\mathrm{PbS}$ lattice and replace $\mathrm{Pb}^{2+}$ ions, thereby improving its optoelectrical properties to a large extent. Reported results have shed light on the relationship between the morphology, optical and electrical properties of the $\mathrm{Cu}$-doped films. In this report, the structural, morphological, optical and electrical properties of $\mathrm{Cu}$-doped $\mathrm{PbS}$ films were investigated.

\section{Experimental procedure}

The glass substrates and the beakers were sequentially cleaned in an ultrasonic cleaner with acetone, absolute ethanol and deionized water. All the films were deposited on glass substrates using chemical bath deposition.

The chemical reagents used in the present work were of analytical grade. The initial solution was prepared by the sequential addition of: $0.17 \mathrm{M}$ lead acetate $\left(\mathrm{Pb}\left(\mathrm{CH}_{3} \mathrm{COOH}\right)_{2} \cdot 3 \mathrm{H}_{2} \mathrm{O}\right), 0.57 \mathrm{M}$ sodium hydroxide $(\mathrm{NaOH})$, the certain amount of sodium citrate and distilled water. Different quantities of $\mathrm{Cu}\left(\mathrm{CH}_{3} \mathrm{COOH}\right)_{2} \cdot \mathrm{H}_{2} \mathrm{O}$ were added to each initial solutions as dopant sources at the concentrations of $0,1,2,3$, and 4 at. $\%$. The $\mathrm{pH}$ value of the solution was adjusted by adding $\mathrm{NaOH}$. Then, $0.2 \mathrm{M}$ thiourea was added to the initial solution, and the color of the reaction solution would change. The cleaned glass substrates were placed vertically in the beaker, which immersed into water heating bath circulator placed on heating magnetic agitator. The reaction temperature was maintained at $75{ }^{\circ} \mathrm{C}$. After $1 \mathrm{~h}$, we took out the substrates and washed them with deionized water. Finally, the compact and smooth $\mathrm{PbS}$ films were obtained.

The crystal structure, crystallinity and phase of the films were characterized by X-ray diffraction using a BRUKER D8 ADVANCE with a $\mathrm{Cu}-\mathrm{K}$ alpha line $(\lambda=1.5406 \AA)$. The morphology and microstructure of the films were studied with a scanning electron microscope (ZEISS Ultra 55). The element composition of the films were detected by the energy dispersive X-ray spectroscopy (EDX). Optical band gap spectra and optical transmission of the films were 
determined by UV-Vis-NIR spectrometer (PerkinElmer Lambda 950) at room temperature. Electrical properties of the films were performed using Hall Effect measurement (HALL 8800).

\section{Results and discussion}

\subsection{Structure}

Fig. 1 is the X-ray diffraction patterns of all the prepared films, and Table 1 is Structural parameters of $\mathrm{Cu}$-doped $\mathrm{PbS}$ films with various $\mathrm{Cu}$ concentrations. In the Fig. 1 , the observed peaks at $25.96^{\circ}, 30.07^{\circ}$, $43.06^{\circ}, 50.98^{\circ}, 53.41^{\circ}, 62.54^{\circ}, 68.88^{\circ}, 70.97^{\circ}$ and $78.92^{\circ}$ correspond to the crystalline planes of (111), (200), (220), (311), (222), (400), (331), (420) and (422), respectively. These diffraction peaks can be indexed to cubic crystallinity phase, according with database values [PDF No.050592]. The diffraction peaks of $\mathrm{PbS}$ were sharp and intense, indicating their highly crystalline nature. No impurity peaks are observed, confirming the high purity of the products. The peak in the (lllll) plane gradually becomes weaker as the $\mathrm{Cu}$ concentration increases. The doped $\mathrm{PbS}$ has a preferred orientation along the (200) plane, probably because the $\mathrm{Cu}$ ions preferentially enter the (200) plane to change the relative growth rate of the crystal plane. It is the most obvious that the peak intensity of this plane increases first and then decreases with $\mathrm{Cu}$ concentration, while FWHM decreases first and then increases. A possible explanation is that when a small amount of $\mathrm{Cu}$ ions are incorporated, $\mathrm{Cu}$ ions preferentially enter the defect sites in the crystal to reduce the free energy of the system, which can be reflected by the significant decrease in micro strain and dislocation density in the Table1, thus promoting the crystallization process.

With the increasing dopant content, the intensity of main peaks decreases and the crystallinity starts to deteriorate. Because $\mathrm{Cu}$ ions have a small ionic radius, $\mathrm{Cu}$ ions may enter new defective locations. The values of micro strain and dislocation density gradually increase after reaching the minimum, which has a negative impact on the crystallization process of the films. High $\mathrm{Cu}$ concentration leads to disordered crystal structure and some defects, which effectively reduce the strength of the lead sulfide phase. As the concentration of $\mathrm{Cu}$ ions in the solution further increases, the grain size will decrease. ${ }^{26}$ This may be resulted from the fact that $\mathrm{Pb}$ ions are replaced by $\mathrm{Cu}$ ions, resulting in lattice contraction.

Fig. 1 and Table 1 show that the (200) peak position of the $\mathrm{Cu}: \mathrm{PbS}$ films shifted slightly to the higher $2 \theta$ value compared to the undoped film. The $2 \theta$ value increases monotonically with increasing $\mathrm{Cu}$ concentration, which implies that the lattice constant changed after $\mathrm{Cu}$ doping. This result further affects the grain size.

The XRD peaks of 1 at. \% $\mathrm{Cu}: \mathrm{PbS}$ nanofilm are sharper and higher in intensity, indicating the increase of grain size. These peaks become broader with increasing $\mathrm{Cu}$ concentration, which agrees with the decrease in the crystallite size. The crystallite size $(D)$ can be

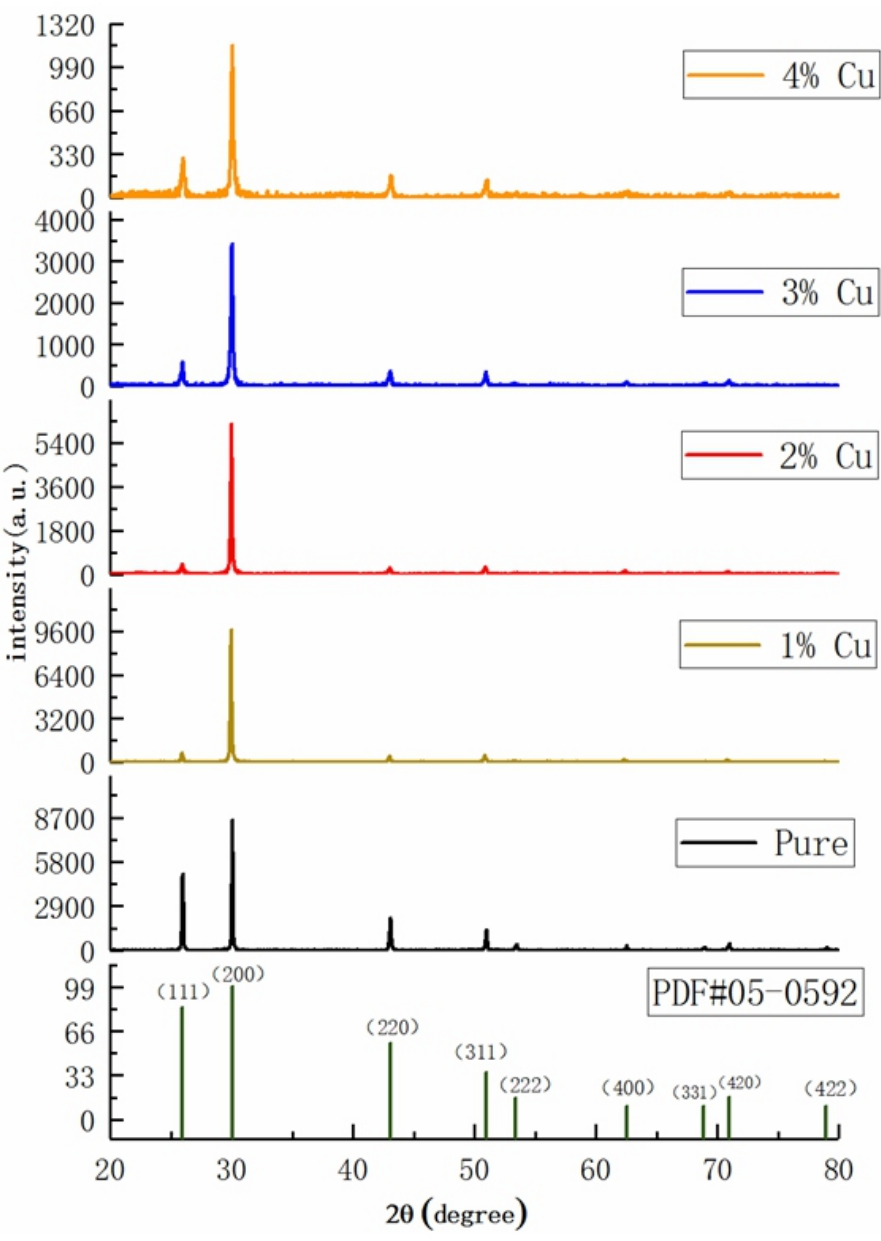

Fig. $1 \mathrm{XRD}$ patterns for the undoped and $\mathrm{Cu}$-doped $\mathrm{PbS}$ films.

Table 1 Structural parameters of $\mathrm{Cu}$-doped $\mathrm{PbS}$ films with various $\mathrm{Cu}$ concentrations.

\begin{tabular}{|c|c|c|c|c|c|c|c|}
\hline $\mathrm{Cu}$ & $(h k l)$ & $2 \theta$ & FWHM & Lattice & Crystallite & Micro & Dislocation \\
\hline Content & & Value & (radian) & constant & size & Strain & Density \\
\hline (at. \%) & & $\left({ }^{\circ}\right)$ & & $a(\AA)$ & $D(\mathrm{~nm})$ & $\varepsilon\left(10^{-3}\right)$ & $(\rho) \times 10^{3}\left(\mathrm{~cm}^{-2}\right)$ \\
\hline $0 \%$ & (200) & 29.848 & 0.383 & 0.5982 & 23.9 & 1.6148 & 1.7579 \\
\hline $1 \%$ & (200) & 29.965 & 0.130 & 0.5959 & 70.3 & 0.5479 & 0.2024 \\
\hline $2 \%$ & (200) & 29.987 & 0.142 & 0.5955 & 64.4 & 0.5985 & 0.2414 \\
\hline $3 \%$ & (200) & 30.041 & 0.200 & 0.5944 & 45.7 & 0.8428 & 0.4789 \\
\hline $4 \%$ & (200) & 30.043 & 0.209 & 0.5943 & 43.7 & 0.8808 & 0.5229 \\
\hline
\end{tabular}


calculated from the full width at half maximum (FWHM) values of the (200) diffraction peaks for various $\mathrm{Cu}$ concentration using Scherrer formula: ${ }^{27}$

$$
D=\frac{0.9 \lambda}{\beta \operatorname{Cos} \theta}
$$

The micro-strain $(\varepsilon)$ is determined using the relation: $:^{28}$

$$
\varepsilon=\frac{\beta \operatorname{COS} \theta}{4}
$$

The dislocation density $(\delta)$ values of films is calculated using the formula: ${ }^{29}$

$$
\delta=\frac{1}{D^{2}}
$$

where $\beta$ is the full width at half maximum of the diffraction peaks, $\lambda$ is the wavelength of incident X-ray, and $\theta$ is the diffraction angle. The micro-structural parameters of $\mathrm{Cu}$ doped $\mathrm{PbS}$ films, including d-spacing, calculated grain size, FWHM, micro strain, dislocation density, are given in Table 1. The crystallite sizes corresponding to (200) plane start to decrease with the increasing $\mathrm{Cu}$ doping concentration. Thus, when the crystallite size is very small, the broadening of the X-ray diffraction peaks will occur. Then, the crystallite size decreases to release the strain in order to stabilize the crystal structure. ${ }^{30}$

The dislocation density of $\mathrm{Cu}$-doped $\mathrm{PbS}$ films are generally smaller than the undoped PbS film. This means that the copper has a great influence on the structure of the $\mathrm{PbS}$ nanofilms. The incorporation of copper can significantly reduce the dislocation defects of the $\mathrm{PbS}$ films. However, as the $\mathrm{Cu}$ concentration increases, this trend is gradually getting weaker. Our findings lead us to conclude that a moderate amount of copper impurities can cause slightly shifts of the position of $\mathrm{Pb}$ ions, eliminates some dislocations, relaxes the micro strain, and enhances the stability of the lattice.

\subsection{Morphology}

Fig. 2 shows the effects of $\mathrm{Cu}$ on the particles size and surface morphology of the PbS films. It can be seen that the surface continuity of the film is very good, and the entire substrate is covered by the PbS film without voids or cracks. The formation of films generally has two processes: the nucleation process and the growth process. In order to obtain the same-sized particles on the substrates, the two processes should be separated as much as possible so that the crystal nucleus grows simultaneously without the formation of new nuclei. There (That there) is a small amount of agglomerates on the films, which is caused by the simultaneous nucleation process and growth process. From Fig. 2 , we find that the size of the particles gradually decreases as the doping concentration increases. We believe that the introduction of copper restrains crystal growth.

According to EDX spectra, the existence of $\mathrm{Pb}, \mathrm{S}$ and $\mathrm{Cu}$ elements can be confirmed. The appearance of other peaks is caused by the glass substrate, which does not affect the accuracy of the test. ${ }^{31}$ The atomic percentages of the doping element in each film are 1.49, 2.37, 3.281 and 3.528 at. $\%$ for solutions having 1,2, 3 and 4 at. \% concentrations of $\mathrm{Cu}$, respectively. Errors are within $0.5 \%$ in the normal range. This

(a) Pure $\mathrm{PbS}$
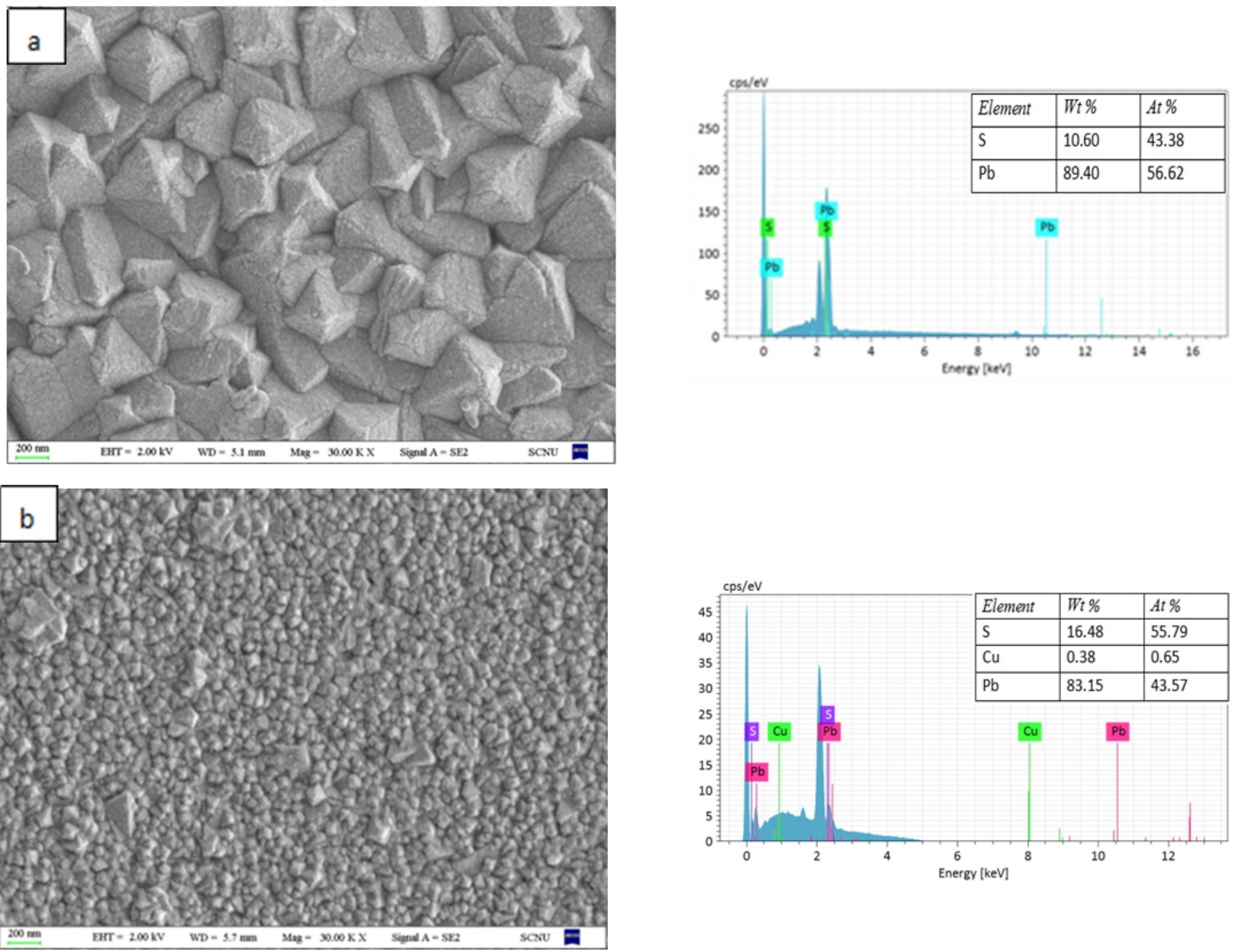

Fig. 2 SEM images and EDX spectra of $\mathrm{PbS}$ nanofilms with various $\mathrm{Cu}$ concentrations. (a): $0 \% \mathrm{Cu},(\mathrm{b}): 1 \% \mathrm{Cu},(\mathrm{c}): 2 \% \mathrm{Cu},(\mathrm{d}): 3 \% \mathrm{Cu}$, and (e):4\% $\mathrm{Cu}$. 
confirmed that $\mathrm{Cu}$ was successfully incorporated into the $\mathrm{PbS}$ films.

The shape of the surface particles varies with the $\mathrm{Cu}$ concentration as shown in Fig. 3, the changing process of crystalline particles can be roughly divided into three stages. In the first stage, the crystal particles exhibit pyramid shape, and in the second stage, the crystal particles appear as cubes or truncated octahedrons similar to football. In the final stage, most of the crystal particles appear as spheres.

\subsection{Growth mechanism}

Fig. 3 depicts the changing process of particles on the surface of the film. We might analyze it by combining XRD pattern. As shown in Fig.
1, when the $\mathrm{Cu}$ concentration is zero, the relative intensity ratio of the (111) peak and the (200) peak is quite large. This means that the growth rate of the surface particles along these two facets is almost the same and the growth of the (111) facet causes many pyramidal particles to appear on the surface. ${ }^{32}$

For pure $\mathrm{PbS}$ film with the pyramidal particles, the main growth element is an anion ligand polyhedron, $\mathrm{Pb}-\mathrm{S}_{6}$ octahedron element. When a low concentration of copper is incorporated, copper ions preferentially enter the crystal lattice from the vertex sites of the octahedral element, thereby promoting the growth of (200) facet, causing the surface particle morphology to be converted into a cube. At the same time, since the copper ion radius is smaller than the lead ion radius, the grown doped (c) $2 \% \mathrm{Cu}$

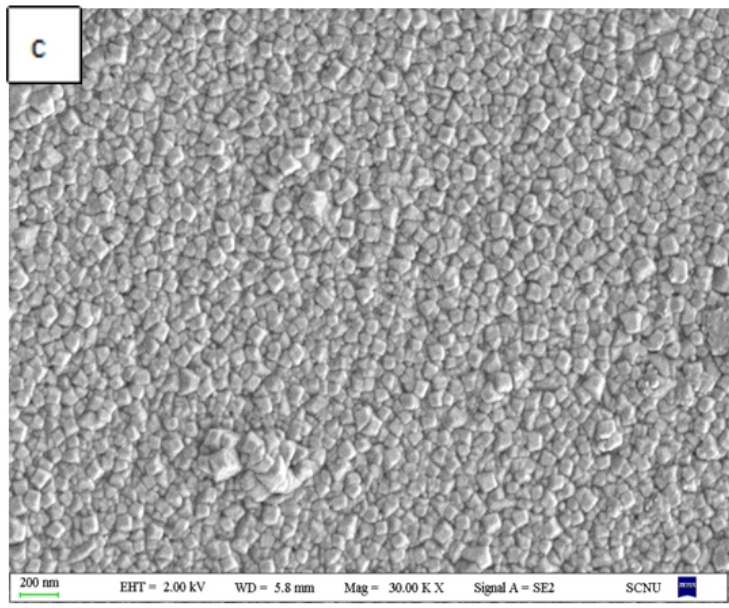

(d) $3 \% \mathrm{Cu}$

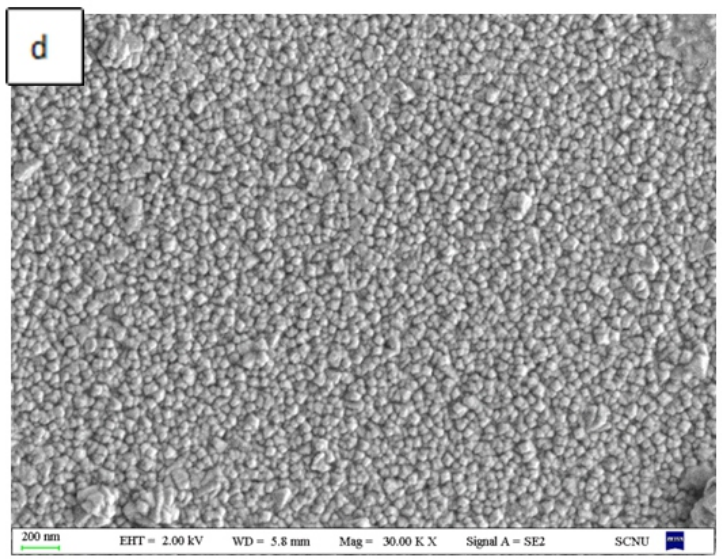

(e) $4 \% \mathrm{Cu}$

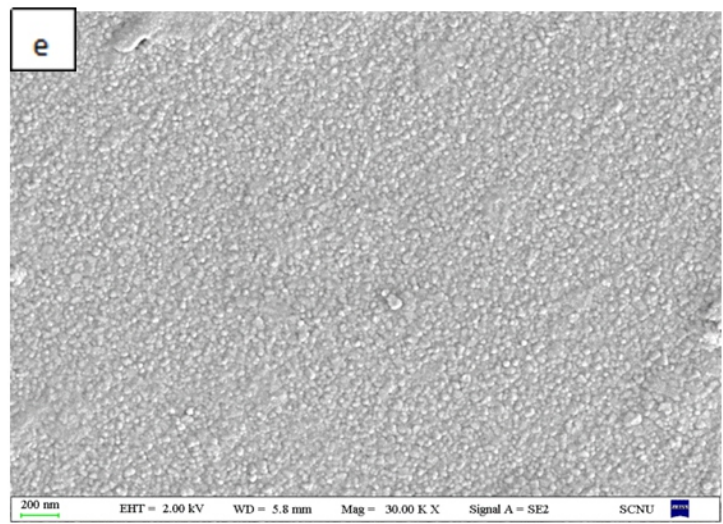

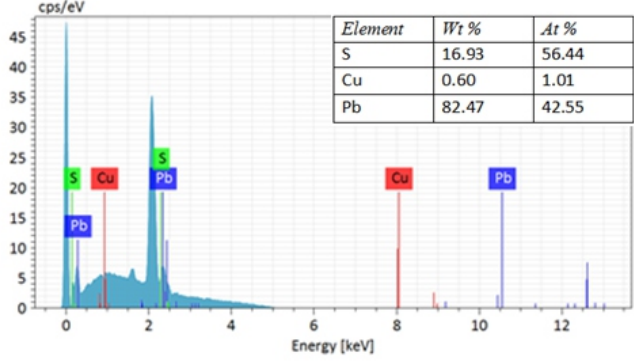
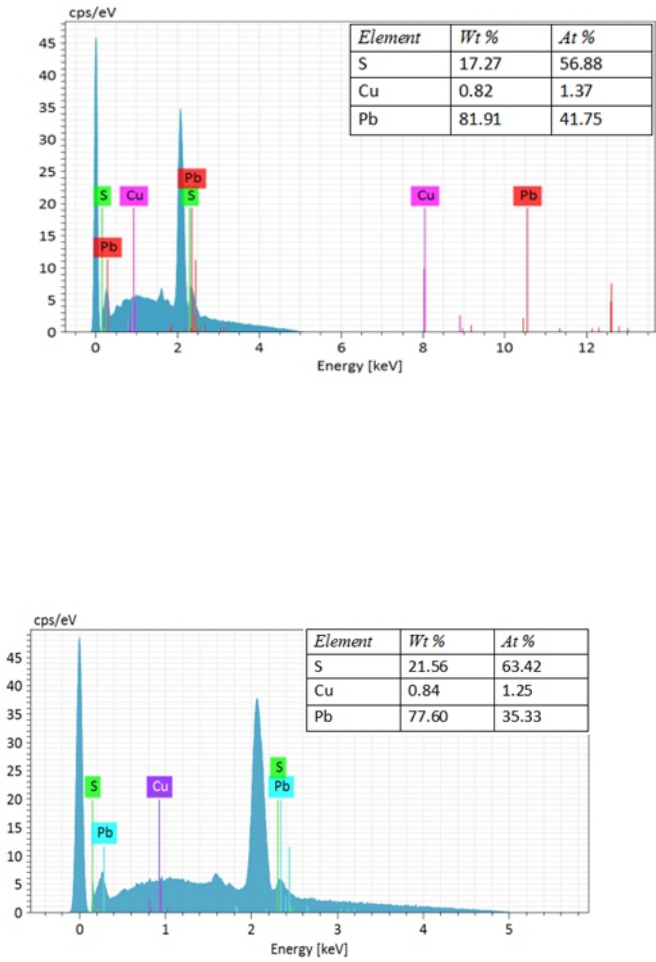

Fig. 2 SEM images and EDX spectra of $\mathrm{PbS}$ nanofilms with various $\mathrm{Cu}$ concentrations. (a): $0 \% \mathrm{Cu},(\mathrm{b}): 1 \% \mathrm{Cu},(\mathrm{c}): 2 \% \mathrm{Cu},(\mathrm{d}): 3 \% \mathrm{Cu}$, and (e):4\%Cu. 
octahedral element has lattice distortion and stress at the vertex sites, which increases with the increase of copper concentration. As the copper concentration continues to increase, the strain energy at the vertex sites becomes large enough, and become a barrier that blocks the entry of copper ions. At this time, copper ions preferentially enter the crystal lattice from the side of the octahedral element and the growth rate of the (111) surface rises, which causes the surface morphology changes into a truncated octahedron shape. While the copper concentration continues to increase, the truncated octahedron tends to be equiaxed grain changes, close to a spherical shape.

Moreover, due to the incorporation of $\mathrm{Cu}$ ions, more favorable positions are provided for the nucleation of the new phase, and more fine new crystal nucleus are formed, resulting in finer and denser particles on the surface of the doped film. Therefore, we conclude the copper concentration determined the surface growth mechanism of $\mathrm{Cu}$ doped $\mathrm{PbS}$ film.

\subsection{Optical properties}

The transmittance spectra for $\mathrm{Cu}: \mathrm{PbS}$ films are shown in Fig. 4. We observed that $4 \% \mathrm{Cu}$-doped $\mathrm{PbS}$ film has the highest transmittance in the near-infrared region (780 2400nm). The transmittance of $\mathrm{PbS}$ films increases after being doped, and there is a significant blue shift of the transmission peak related to the increase of the band gap.

As shown in Fig. 2 (b) and Fig. 2 (c), we found that the two films are mainly composed of cubes with relatively regular particle shapes and small particle size $((80 \sim 90 \mathrm{~nm})$. This shape feature will help increase the probability of specular reflection and increase transmission. This is consistent with the results shown in Fig. 4. Fig. 2 (d) shows that the surface of the whole $\mathrm{PbS}$ film is relatively flat, the particle size is further reduced $(40 \sim 50 \mathrm{~nm})$ and the shape of the particles is mostly truncated octahedron. The shape of the particles gradually changes from angular to round, meanwhile, the particle size decreases. These lead to an increase in scattering effect and diffuse reflection, and more light is absorbed by the $\mathrm{PbS}$ film during the scattering process.

The transmission spectra show that the transmittance decreases with increasing $\mathrm{Cu}$ concentrations in the range of $780 \mathrm{~nm}$ to $2400 \mathrm{~nm}$. However, when copper is doped at a high concentration $(4 \% \mathrm{Cu})$, the transmittance suddenly increases due to an increase in light scattering losses. An increase in light scattering losses in the spectra range from 780 to $2400 \mathrm{~nm}$, which can be attributed to the morphological features. By observing the SEM image, it can be found that the surface roughness and particle size of the 3\% and $4 \% \mathrm{Cu}$-doped $\mathrm{PbS}$ films are almost the same. We believe that plasmon presented on the surface of the nanostructured semiconductor ${ }^{33}$ plays an important role, as different nanostructures have different gains for plasmon. According to Fig. 4, it can be seen that the nanosphere on the surface of the film has a larger effect on the gain of the plasmon than the nano-truncated octahedron. The stronger the plasmon, the higher the transmittance of light. This is one reason why the transmittance of 3 at. \% Cu-doped $\mathrm{PbS}$ film is lower than that of 4 at.\% Cu-doped PbS film. Based on these results, we conclude that the shape of the surface particles has a great influence on the transmittance of the films, and the film with truncated octahedral particles has the lowest transmittance.

The optical absorption and transmittance spectrum of the PbS films were determined by UV-vis-NIR spectrophotometer. The bandgap value of each sample can be obtained by calculating the optical absorption data using the Tauc formula. ${ }^{34}$

$$
(\alpha h v)=\mathrm{A}\left(h v-E_{g}\right)^{\mathrm{n}}
$$

where $v$ is incident photon frequency, $h$ is the Planck constant, $A$ is a constant, and $E_{g}$ is the energy gap between the bottom of the conduction

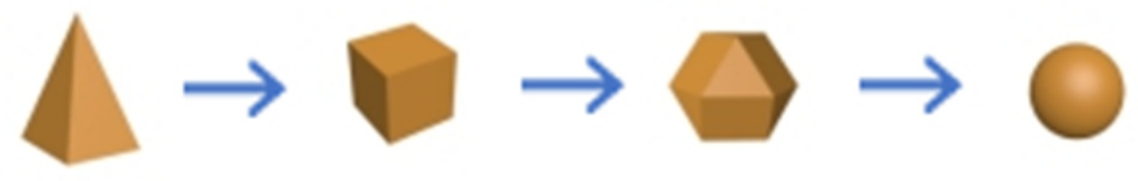

Fig. 3 The changing process of surface particles.

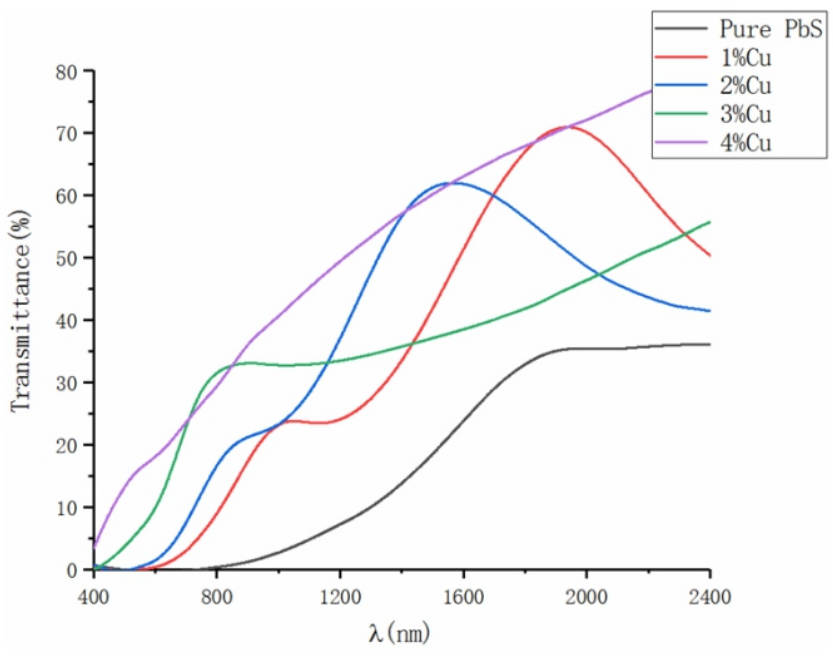

Fig. 4 Variation of transmittance with wavelength for $\mathrm{Cu}$ : $\mathrm{PbS}$ films.

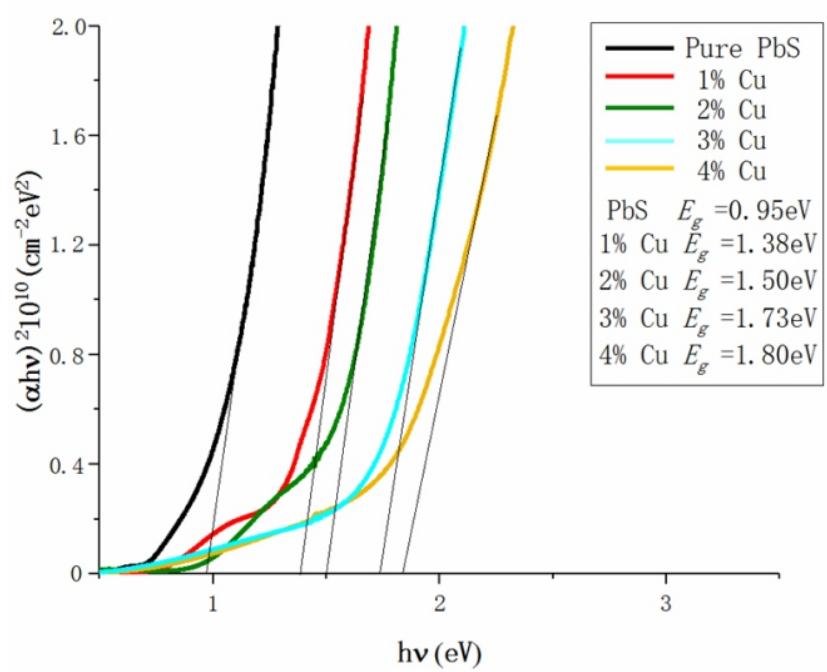

Fig. 5 Optical band gap energy plots at different $\mathrm{Cu}$ concentrations. 
band and top of the valence band, and since $\mathrm{PbS}$ is a direct bandgap semiconductor, $\mathrm{n}$ is equal to $1 / 2$ in this formula. Absorption coefficient $(\alpha)$ can be calculated from the following equation. ${ }^{35}$

$$
\alpha=2.303 \mathrm{~A} / \mathrm{t}
$$

where $A$ is absorbance and $\mathrm{t}$ is thickness of thin film. Fig. 5 shows the optical band gap energy plots of various $\mathrm{PbS}$ films at different $\mathrm{Cu}$ concentrations. The straight-line portion is extended to the abscissa. When $\alpha$ is equal to 0 , the corresponding value of $h v$ is the band gap value of the $\mathrm{PbS}$ film.

According to the Fig. 5, we can intuitively analyze the optical properties of undoped and $\mathrm{Cu}$-doped $\mathrm{PbS}$ nanofilms, and study the effect of copper on the optical properties of $\mathrm{PbS}$ nanofilms. It is observed that the optical band gap changed with the concentration of the dopant in a regular manner. The band gap of pure $\mathrm{PbS}$ film is about $0.95 \mathrm{eV}$, the band gap of the PbS film with 4 at. \% $\mathrm{Cu}$ is about $1.8 \mathrm{eV}$. The band gap gradually increased with $\mathrm{Cu}$ concentration.

As can be seen from Table 1, the Cu-doped PbS films have a larger crystallite size, which causes the influence of quantum size on the band gap to decrease. However, the influence of the copper on the band gap is dominant, which leads to a larger band gap. A possible explanation is that the $3 \mathrm{~d}$ electrons of $\mathrm{Cu}$ form an impurity level above the Fermi surface, causing the Fermi surface to sink slightly into the valence band. At the same time, the bottom of the conduction band is raised to a certain extent, resulting in an increase in band gap. When $\mathrm{Cu}$ is incorporated into the $\mathrm{PbS}$ films, the absorption edge has a corresponding gradual blue shift with increasing $\mathrm{Cu}$ content. The band gap of p-type heavy doped $\mathrm{PbS}$ nanoflims will be broadened because the Fermi level is located in the valence band. And the full band blocks the thermal excitation and the photo excitation, so the band gap absorption moves toward the high-energy direction. ${ }^{36}$

The experimental data show that dopant can rise the optical band gap of $\mathrm{PbS}$ films. Especially 2 at. \% $\mathrm{Cu}: \mathrm{PbS}$ nanofilm with $E_{g}$ equal to $1.5 \mathrm{eV}$ matched well with the optimum value of theoretical band gap for absorbing sunlight from the visible to near-infrared band and for good conversion of solar energy to electricity. ${ }^{37}$

\subsection{Electrical properties}

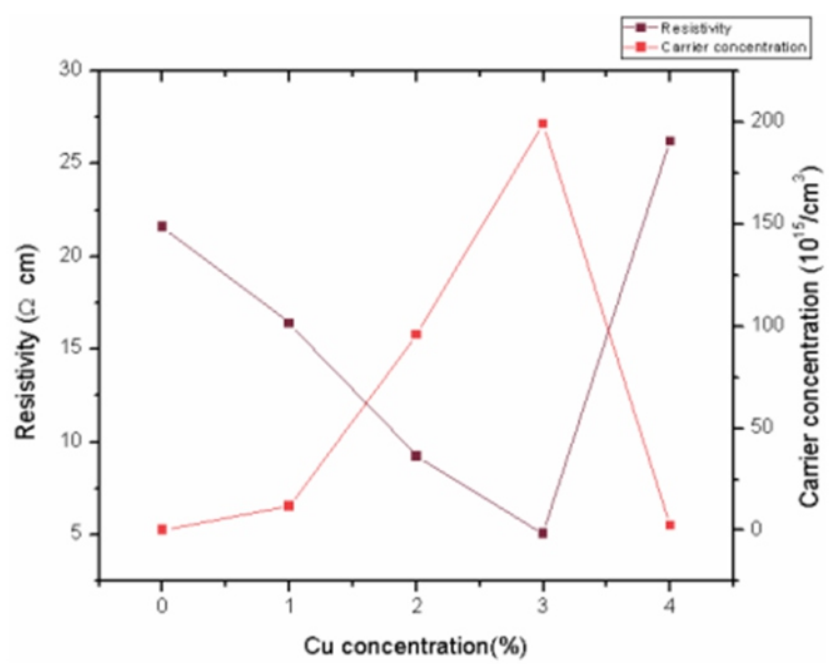

Fig. 6 Resistivity and carrier concentration of $\mathrm{Cu}$-doped $\mathrm{PbS}$ films with various $\mathrm{Cu}$ concentrations.
Fig. 6 shows the resistivity and carrier concentration of $\mathrm{Cu}$-doped $\mathrm{PbS}$ films with various $\mathrm{Cu}$ concentrations. We can find that the overall trend of resistivity drops first and then rises, while the overall trend of carrier concentration is opposite to that of resistivity.

When the amount of copper rises from $0 \%$ to $3 \%$, the resistivity continuously decreases. The electrical properties of $\mathrm{PbS}$ films are improved by the incorporation of copper. The $\mathrm{PbS}$ films are measured by the Hall Effect measurements to be a p-type semiconductor. Since the carriers of the p-type semiconductor are mainly holes, the concentration of holes has a major influence on the resistivity. Therefore, when the $\mathrm{Cu}$ concentration is continuously increased, it contributes to increase the hole carrier density in the valence band and reduce the value of resistivity.

When the $\mathrm{Cu}$ concentration increases from $3 \%$ to $4 \%$, we find from the SEM images that the particles on the surface become finer. The information given by XRD also show that the FWHM increases, implying that the particle size becomes smaller. So the surfaces of the films are dominated by fine polycrystals, which leads to an increase in grain boundaries and lattice defects. ${ }^{38}$ Moreover, the dislocation defects and strain defects are beneficial to the grain boundary scattering and defect scattering of electrons. The combination of these factors ultimately leads to an increase in resistivity.

While the doping concentration increases from $0 \%$ to $1 \%$, the carrier concentration does not change significantly. Due to the low concentration of doped copper, it has little effect on the increase of carrier concentration. When the doping concentration is equal to $3 \%$, the carrier concentration reaches a maximum value. The increased carrier concentration of the $\mathrm{Cu}$-doped $\mathrm{PbS}$ films can be attributed to the midgap states created by $\mathrm{Cu}$ doping - these traps and screens electrons. ${ }^{39}$ However, when the copper content furtherly increased to $4 \%$, some $\mathrm{Cu}$ atoms can not occupy lattice sites. On the contrary, they formed neutral defects and became ineffective. ${ }^{40}$ This may be an important reason for the decrease in carrier concentration at high $\mathrm{Cu}$ concentration. In addition, $\mathrm{PbS}$ film with nanosphere structure has great gain on surface plasmon. Strong plasmon means more excitons and lower dissociation rate of excitons, which also leads to the carrier concentration decrease dramatically at high $\mathrm{Cu}$ concentration. At the same time, strong plasmon can enhance the surface electron scattering and greatly increase the resistance. Therefore, when the copper concentration rises from $3 \%$ to $4 \%$, both of them have abnormal changes.

The data obtained by the Hall Effect measurement shows that the optimum $\mathrm{Cu}$ concentration is $3 \%$, and the $\mathrm{PbS}$ nanofilm has the lowest resistivity and the highest carrier concentration. $\mathrm{PbS}$ nanofilms are found to be suitable as an absorbing material in thin film solar cells due to the improved optoelectronic properties achieved through copper doping.

\section{Conclusion}

Different concentrations of $\mathrm{Cu}$-doped $\mathrm{PbS}$ films were prepared by CBD method. It can be seen from XRD pattern that the lower $\mathrm{Cu}$ concentration greatly improves the crystallinity of $\mathrm{PbS}$. However, as the $\mathrm{Cu}$ concentration increases, the nanofilm will produce more defects and strains, which has an adverse effect on the crystallinity of the $\mathrm{PbS}$ nanofilms. The SEM images show that the particle size decreases with the increase of $\mathrm{Cu}$ concentration. The surface morphology of $\mathrm{Cu}$-doped $\mathrm{PbS}$ films changes from pyramid into cube, truncated octahedron and sphere consequently. The $\mathrm{Cu}$ concentration determined the growth mechanism of $\mathrm{Cu}$-doped $\mathrm{PbS}$ film. Under the action of $3 \mathrm{~d}$ state electrons of copper, the band gap will be widened. By analyzing the transmission and morphology, another interesting finding is that 3 at. \% 
Cu-doped PbS film with truncated octahedral particles has the lowest transmittance, which is important for the study of optical properties of nanofilms. When the $\mathrm{Cu}$ concentration is equal to $3 \%, \mathrm{PbS}$ film has the largest carrier concentration and the lowest resistivity, reflecting the best electrical properties. Therefore, in order to obtain excellent optical and electrical properties, the sample is required to satisfy the following conditions: a higher doping concentration, a smoother film surface and the surface should be dominated by small-truncated octahedral particles. These conditions can help to improve the optical and electrical properties of the nanofilms. Our results reveal that $\mathrm{Cu}$-doped $\mathrm{PbS}$ nanofilms would have more hopeful prospects in optoelectronic devices, such as solar cells application.

\section{Conflict of interest}

"There are no conflicts to declare".

\section{Acknowledgement}

We kindly acknowledge financial support from the National Natural Science Foundation of China [No. 11674106, No.51505158 and No. 51672090].

\section{References}

1. R. K. Joshi and H. K. Sehgal, Physica E: Low-dimensional Systems and Nanostructures, 2004, 23, 168-170.

2. E. Yücel and Y. Yücel, Ceram. Int., 2017, 43, 407-413.

3. A. U. Perera, P. Jayaweera, G. Ariyawansa, S. Matsik, K. Tennakone, M. Buchanan, H. Liu, X. Su and P. Bhattacharya, Microelectr. J., 2009, 40, 507511.

4. E. Pentia, L. Pintilie, I. Matei, T. Botila and I. Pintilie, Infrared Phys. Techn., 2003, 44, 207-211.

5. E. Indrea and A. Barbu, Appl. Surf. Sci., 1996, 106, 498-501.

6. T. Fu, Sensors and Actuators B: Chemical, 2009, 140, 116-121.

7. S. Kaci, A. Keffous, S. Hakoum, M. Trari, O. Mansri and H. Menari, Appl. Surf. Sci. 2014, 305, 740-746.

8. T. V. Beatriceveena, E. Prabhu, A. Sree Rama Murthy, V. Jayaraman and K. I. Gnanasekar, Appl. Surf. Sci., 2018, 456, 430-436.

9. J. Hernández-Borja, Y. Vorobiev and R. Ramírez-Bon, Sol. Energ. Mat. Sol. C., 2011, 95, 1882-1888.

10. Z. Zhang, C. Shi, J. Chen, G. Xiao and L. Li, Appl. Surf. Sci., 2017, 410, 813.

11. X. Shen, Z. Li, Y. Cui and Y. Pang, Int. J. Electrochem. Sci, 2011, 6, 35253535 .

12. R. Bai, D. Kumar, S. Chaudhary and D. K. Pandya, Acta Mater, 2017, 131, 11-21.

13. S. Seghaier, N. Kamoun, R. Brini and A. Amara, Mater. Chem. Phys., 2006, 97, 71-80.

14. R. K. Joshi, A. Kanjilal and H. K. Sehgal, Appl. Surf. Sci., 2004, 221, 43-47.
15. K. Preetha, K. Murali, A. Ragina, K. Deepa and T. Remadevi, Curr. Appl. Phys. 2012, 12, 53-59.

16. B. Thangaraju and P. Kaliannan, Semicond. Sci. Tech., 2000, 15, 849.

17. P. S. Mangesh Waghmare, Prashant Patil, Vishal Kadam, Habib Pathan and Ashok Ubale, Spray Pyrolytic Deposition of Zirconium Oxide Thin Films: Influence of Concentration on Structural and Optical Properties, Engineered Science, 2018.

18. S. Kumar, T. Sharma, M. Zulfequar and M. Husain, Physica B, 2003, 325, 8 16.

19. D. Atwa, I. Azzouz and Y. Badr, Appl. Phys. B, 2011, 103, 161-164.

20. M. Sharon, K. Ramaiah, M. Kumar, M. Neumann-Spallart and C. LevyClement, J. Electroanal. Chem. 1997, 436, 49-52.

21. S. Ravishankar, A. Balu, K. Usharani, S. Balamurugan, D. Prabha and V. Nagarethinam, Optik-International Journal for Light and Electron Optics, 2017, 134, 121-127.

22. L. Maskaeva, V. Markov, E. Mostovshchikova, V. Voronin, A. Pozdin and S. Santra, J. Alloy. Compd., 2018, 766, 402-409.

23. S. Rajathi, K. Kirubavathi and K. Selvaraju, Journal of Taibah University for Science, 2017, 11, 1296-1305.

24. S. R. Castilla, M. Z. Tototzintle, R. B. L. Flores, L. C. Lima and O. P. Moreno, Journal of Materials Science and Engineering. A, 2013, 3, 305.

25. R. Geethu, R. Jacob, T. Shripathi, G. Okram, V. Ganesan, S. Tripathi, A. Fatima, P. Sreenivasan, K. Urmila and B. Pradeep, Appl. Surf. Sci., 2012, 258, 6257-6260

26. R. S. S. Saravanan, M. Meena, D. Pukazhselvan and C. Mahadevan, J. Alloy Compd., 2015, 627, 69-77.

27. G. Williamson and R. Smallman, Philos. Mag., 1956, 1, 34-46.

28. H. Ong, A. Zhu and G. Du, Appl. Phys. Lett., 2002, 80, 941-943.

29. A. Kariper, E. Güneri, F. Göde, C. Gümüş and T. Özpozan, Mater. Chem. Phys., 2011, 129, 183-188.

30. R. Palomino-Merino, O. Portillo-Moreno, L. Chaltel-Lima, R. G. Pérez, M. de Icaza-Herrera and V. Castaño, J. Nanomater, 2013, 2013, 45.

31. A. Fouda, M. Marzook, H. A. El-Khalek, S. Ahmed, E. Eid and A. El Basaty, Silicon, 2017, 9, 809-816.

32. B. Touati, A. Gassoumi and N. K. Turki, J. Mater. Sci-Mater. El., 2017, 28, 1 -

33. T. Z. Hua and D. H. Ming, ACTA PHYS. SIN-CH ED, 2017, 66.

34. S. Kumar, Z. H. Khan, M. M. Khan and M. Husain, Curr. Appl. Phys., 2005, 5, 561-566.

35. K. Nama Manjunatha and S. Paul, Appl. Surf. Sci., 2015, 352, 10-15.

36. E. Burstein, Phys. Rev., 1954, 93, 632.

37. J. Feng, X. Huang, W. Chen, J. Wu, H. Lin, Q. Cheng, D. Yun and F. Zhang, Vacuum, 2016, 126, 84-90.

38. T. Tohidi, K. Jamshidi-Ghaleh, A. Namdar and R. Abdi-Ghaleh, Mat. Sci. Semicon. Proc. 2014, 25, 197-206.

39. Z. Huang, X. Zou and H. Zhou, Mater. Lett., 2013, 95, 139-141.

40. B. Touati, A. Gassoumi, S. Alfaify and N. Kamoun-Turki, Mater. Sci. Semicon. Proc., 2015, 34, 82-87.

Publisher's Note Engineered Science Publisher remains neutral with regard to jurisdictional claims in published maps and institutional affiliations. 